\title{
Characteristics Analysis on Short-Time Heavy Rainfall during the Flood Season in Shanxi Province, China
}

\author{
Xiaoting Tian ${ }^{1,2}$, Dongliang $\mathrm{Li}^{1 *}$, Jinhong Zhou ${ }^{2}$, Yaqing Zhou ${ }^{3}$, Zexiu Zhang² \\ ${ }^{1}$ Key Laboratory of Meteorological Disaster, Ministry of Education (KLME)/Joint International Research Laboratory of \\ Climate and Environment Change (ILCEC)/Collaborative Innovation Center on Forecast and Evaluation of Meteorological \\ Disasters (CIC-FEMD), Nanjing University of Information Science and Technology, Nanjing, China \\ ${ }^{2}$ Taiyuan Meteorological Bureau, Taiyuan, China \\ ${ }^{3}$ Jinzhong Meteorological Bureau, Jinzhong, China \\ Email: *lidl@nuist.edu.cn
}

How to cite this paper: Tian, X. T., Li, D. L., Zhou, J. H., Zhou, Y. Q., \& Zhang, Z. X. (2019). Characteristics Analysis on ShortTime Heavy Rainfall during the Flood Season in Shanxi Province, China. Journal of Geoscience and Environment Protection, 7, 190-203.

https://doi.org/10.4236/gep.2019.73011

Received: February 14, 2019

Accepted: March 26, 2019

Published: March 29, 2019

Copyright $\odot 2019$ by author(s) and Scientific Research Publishing Inc. This work is licensed under the Creative Commons Attribution International License (CC BY 4.0).

http://creativecommons.org/licenses/by/4.0/

\section{(c) (i) Open Access}

\begin{abstract}
In order to provide a reference for the correct forecasting of short-term heavy rainfall and better disaster prevention and mitigation services in Shanxi Province, China, it is very important to carry out systematic research on short-term heavy precipitation events in Shanxi Province. Based on hourly precipitation data during the flood season (May to September) from 109 meteorological stations in Shanxi, China in 1980-2015, the temporal and spatial variation characteristics of short-time heavy rainfall during the flood season are analyzed by using wavelet analysis and Mann-Kendall test. The results show that the short-time heavy rainfall in the flood season in Shanxi Province is mainly at the grade of $20-30 \mathrm{~mm} / \mathrm{h}$, with an average of 97 stations having short-time heavy rainfall each year, accounting for $89 \%$ of the total stations. The short-time heavy rainfall mainly concentrated in July and August, and the maximal rain intensity in history appeared at $23-24$ on June 17, 1991 in Yongji, Shanxi is $91.7 \mathrm{~mm} / \mathrm{h}$. During the flood season, the short-time heavy rainfalls always occur at $16-18 \mathrm{pm}$, and have slightly different concentrated time in different months. The main peaks of June, July and August are at 16, 17 and 18 respectively, postponed for one hour. Short-time heavy rainfall overall has the distribution that the south is more than the north and the east less than the west in Shanxi area. In the last 36 years, short-time heavy rainfall has a slight increasing trend in Shanxi, but not significant. There is a clear 4-year period of oscillation and inter-decadal variation. It has a good correlation between the total precipitation and times of short-time heavy rainfall during the flood season.
\end{abstract}




\section{Keywords}

Flood Season, Short-Time Heavy Rainfall, Temporal and Spatial

Distribution, Shanxi Province

\section{Introduction}

Short-term heavy precipitation refers to the weather phenomenon in which the precipitation intensity is large in a short period of time, and its rainfall reaches or exceeds a certain amount, which is one of the main extreme precipitation weather (Yang et al., 2018). With the increase in time and spatial resolution of precipitation observations in recent years, hourly precipitation is used to define strong precipitation. According to the National Short-Term Nowcasting Regulations, this paper defines short-term strong precipitation as precipitation with an hourly rainfall of $\geq 20 \mathrm{~mm}$. Due to the high concentration of precipitation in time, it is easy to form flash floods, causing waterlogging in farmland, urban shackles, and even secondary disasters such as mudslides and flash floods, causing major economic losses and casualties. Therefore, short-term heavy precipitation has attracted the attention of many scholars at home and abroad.

Chen et al. (2013) studied the characteristics of short-term heavy rainfall with hourly rainfall $\geq 10,20,30,40,50 \mathrm{~mm} / \mathrm{h}$. The results show that the sub-frequency geographical distribution of China's short-term heavy precipitation is similar to heavy rain $(\geq 50 \mathrm{~mm} / \mathrm{d})$. The distributions are very similar, but the short-term heavy precipitation above $50 \mathrm{~mm} / \mathrm{h}$ has a very low frequency and a significant difference in geographical distribution. Zhang et al. (2011) analyzed the trends of precipitation time, hourly rain intensity, extreme precipitation time and extreme precipitation intensity in different seasons in analyzed Southwest China. Yao et al. (2010) use the data of 485 stations in China from 1991 to 2005; it is concluded that the area with the highest frequency of rain intensity above 4 $\mathrm{mm} / \mathrm{h}$ is on the southern coast, and the daily variation of the frequency of rain intensity is different in each region. Han \& Miao (2012), Yin et al. (2012) and others (Cai et al., 2014; Peng et al., 2012; Hao et al., 2012; Yang et al., 2010; Guo et al., 2007; Yin et al., 2010; Shen et al., 2015; Wang \& Wang, 2013; Gu, 2013; Wang et al., 2016; Shen et al., 2017) analyzed short-term heavy rainfall in various regions of the country from different aspects.

On July 19, 2016, there was a rare continuous heavy rain and heavy rain in Shanxi. From 20:00 on July 18 to 20:00 on the 19th, there were 61 meteorological stations with heavy rainfall or heavy rains in 24 hours. Among them, 8 counties and cities were heavy rains, and the number of heavy rains in one hour exceeded that of meteorology. The extreme value was since the record (Wang et al., 2017). We call this precipitation process as "July 19th Heavy Rainstorm". It has a long period of precipitation, concentrated precipitation and large precipitation, and there are many short-term heavy precipitations, which have caused urban floods, 
traffic jams, road damage, house damage, farmland waterlogging, etc. in some areas. Recent studies on precipitation in Shanxi show that precipitation in Shanxi Province has generally decreased, and extreme precipitation events have also tended to decrease. Although the precipitation in the main flood season in most parts of Shanxi Province showed a downward trend, the precipitation with daily precipitation greater than $30 \mathrm{~mm}$ and $50 \mathrm{~mm}$ increased, especially in the central region, indicating that the extreme precipitation events in Shanxi Province during the main flood season increased (Zhao et al., 2006; Zhang et al., 2008; Li et al., 2010; Wang et al., 2012).

Shanxi Province is located in the middle of the Yellow River in the western part of China's North China Plain and on the eastern edge of the Loess Plateau. It is a transitional area between North China and Northwest China. In addition, the terrain of Shanxi Province is complex, with eastern mountainous areas, western Suiyuan mountainous areas and central faulted basins. Due to the particularity of the geographical location and the diversity of the terrain in the territory and the rapid development of urbanization, floods, mudslides and landslides caused by heavy precipitation have become an important disaster for the people's lives and property.

Therefore, it is particularly important to carry out systematic research on short-term heavy precipitation events in Shanxi Province. Therefore, this paper analyzes the short-term heavy rainfall in Shanxi Province during the 36-year period from the period of May-September 1980-2015 and its time and space distribution characteristics, in order to provide a reference for Shanxi Province short-term heavy precipitation correct forecast and better disaster prevention and mitigation services.

\section{Data and Methods}

\subsection{Data}

This paper selects 109 weather stations in Shanxi Province (Figure 1) for hourly automatic precipitation data from 1980 to May 2015, and has carried out quality control. The data from 1980 to 2003 were formed on the basis of self-reported precipitation information data; the data from 2003 to 2015 is the automatic station precipitation data (from the Shanxi Meteorological Information Center). At the same time, because the data taken is the "whole-of-clock" data, the short-term heavy precipitation time that exceeds the specified threshold for one consecutive hours is divided into two stages, but the statistical standards of this paper are not met, so the frequency of short-term heavy precipitation should be higher.

\subsection{Methods}

Wavelet analysis (Abdullayev et al., 2017; Joseph et al., 2015; Banović et al., 2013), as the name suggests, is a small waveform. The so-called "small" or "let" means that it has attenuation; the so-called "wave" refers to its volatility, and its 


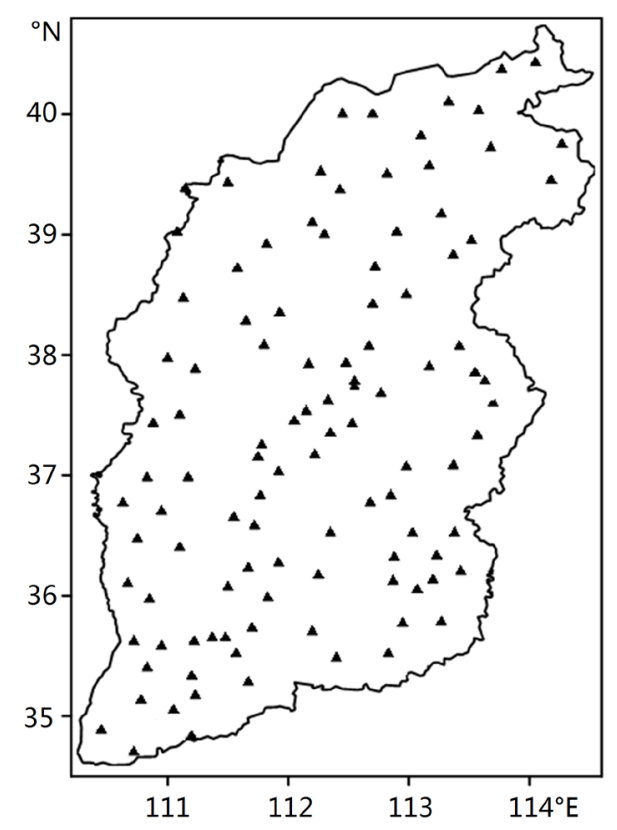

Figure 1. The distribution of meteorological stations in Shanxi, China.

amplitude is positive and negative. The wavelet transform is a localized analysis of the time (space) frequency. It uses a telescopic translation operation to gradually multi-scale the signal (function), and finally achieves time division at high frequency, frequency subdivision at low frequency, and can automatically adapt to time-frequency. Signal analysis requirements so that you can focus on any detail of the signal. Some people refer to the wavelet transform as a "mathematical microscope".

The Mann-Kendall nonparametric statistical method (M-K test) recommended by the World Meteorological Organization and widely used can effectively distinguish whether a natural process is in natural fluctuation or there is a certain change trend. For non-normally distributed hydrometeorological data, the Mann-Kendall rank correlation test has more outstanding applicability. Mann-Kendall is also often used for the detection of precipitation and drought frequency trends under the influence of climate change (Bera, 2017; Ragatoa et al., 2018; Koudahe et al., 2017).

\section{Results and Analysis}

\subsection{Time Distribution Characteristics}

The number of short-term heavy precipitation $(1 \mathrm{~h} \geq 20 \mathrm{~mm})$ occurred in 109 stations in Shanxi Province from May to September 1980-2015 (see Table 1), totaling 3492 times, with an average of 97 stations per year. Among them, the maximum number of precipitation in 1 hour is $20 \mathrm{~mm}-30 \mathrm{~mm}$, accounting for $72.31 \%$ of the total number; $30 \mathrm{~mm}-40 \mathrm{~mm}$ accounts for $19.24 \%$ of the total number; the number of $\geq 50 \mathrm{~mm}$ is 102 times, accounting for $2.92 \%$ of the total 
Table 1. The total, percentage and mean numbers of different grades on precipitation in Shanxi.

\begin{tabular}{cccc}
\hline Grading & Total stations & Percentage $(\%)$ & Average stations \\
\hline$\geq 20(\mathrm{~mm} / \mathrm{h})$ & 3492 & 100 & 97 \\
$20-30(\mathrm{~mm} / \mathrm{h})$ & 2525 & 72.31 & 70.14 \\
$30-40(\mathrm{~mm} / \mathrm{h})$ & 672 & 19.24 & 18.67 \\
$40-50(\mathrm{~mm} / \mathrm{h})$ & 193 & 5.53 & 5.36 \\
$\geq 50(\mathrm{~mm} / \mathrm{h})$ & 102 & 2.92 & 2.83 \\
\hline
\end{tabular}

number, with an average of 2.83 per year, relatively rare. The maximum precipitation in Shanxi Province in 1 hour occurred in Yongji City, Yuncheng City, 23 to 24 hours on June 17, 1991, with a precipitation of $91.7 \mathrm{~mm}$.

Figure 2 shows the time-varying characteristics of short-term heavy precipitation stations in Shanxi Province from May to September in recent 46a. It can be seen that the number of short-term heavy precipitation in Shanxi Province increased slightly in the past 36 years, but it was not obvious. The trend coefficient was 0.27 , which did not pass the 0.05 significant test. The short-term heavy precipitation in the flood season in Shanxi Province showed obvious interdecadal variations. In 1986-1998 and 2008-2014, the short-term heavy precipitation stations in Shanxi Province were more frequent, and the rest of the period was less.

From the above analysis, it is found that the number of short-term heavy precipitation in Shanxi Province shows obvious long-term change trend. In order to further detect the mutation, this paper uses $\mathrm{M}-\mathrm{K}$ method to carry out mutation test on the short-term heavy precipitation station in Shanxi Province near 46a. Figure 3 shows the $\mathrm{M}-\mathrm{K}$ detection curve of short-term heavy precipitation in Shanxi Province. It can be seen that Shanxi Province showed an increasing trend from the late 1980s to the mid-1990s, and it showed a decreasing trend from the mid-late 1990s to the beginning of the 21st century. The two sequence curves intersected in 1986 and 2008, indicating that the precipitation days have changed greatly in the past two years, but the UF curve is in the confidence region, indicating that there is no obvious mutation in the short-term heavy precipitation station in the flood season in Shanxi Province in the past 36 years. This also corresponds to Figure 2.

In order to further explore the periodic characteristics of short-term heavy precipitation stations in Shanxi Province in the recent 36 years, this paper uses the Morlet wavelet method to analyze the short-term heavy precipitation stations in Shanxi Province in the past 36 years (Figure 4). It can be clearly seen from Figure 4(a) that the short-term heavy precipitation stations in Shanxi Province have obvious multi-time scale characteristics in the past 36 years, and there are three scales of 19, 8 and 4 years. There were two shocks on the 19-year scale, 4.5 shocks on the 8 -year scale, and 9 cycles in the 4 -year cycle. And the cyclical changes of the two time scales of 4 and 8 years are relatively stable, while the 19-year periodic changes show unstable characteristics. From the recent 36 


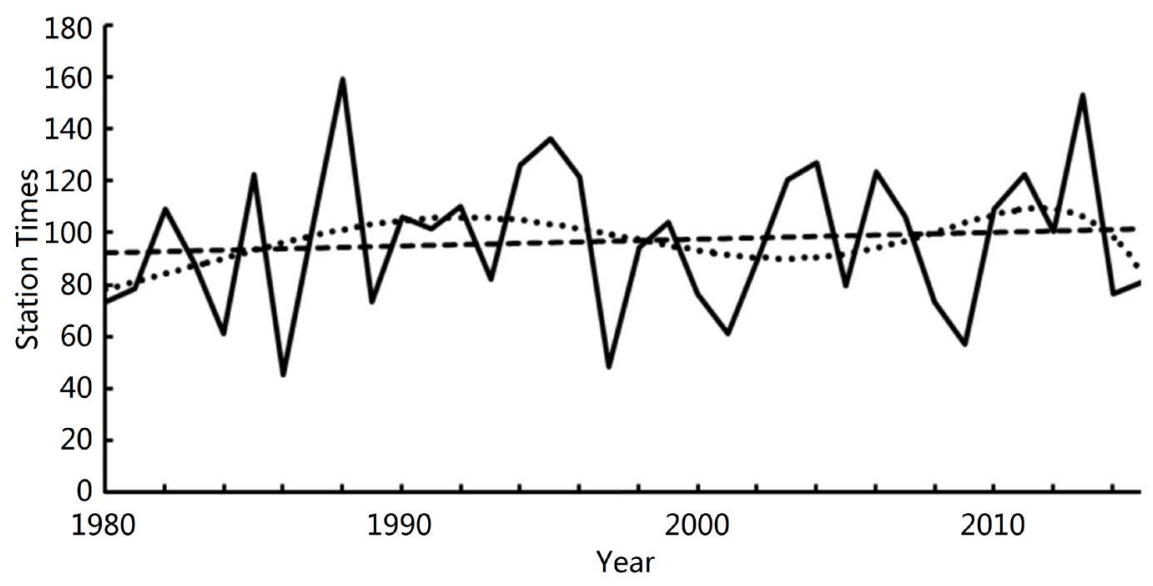

Figure 2. The annual variation (solid line), linear tendency (break line) and 6-order fitting curve (dotted line) of shout-time heavy rainfall number during the flood season in Shanxi in 1980 to 2015.

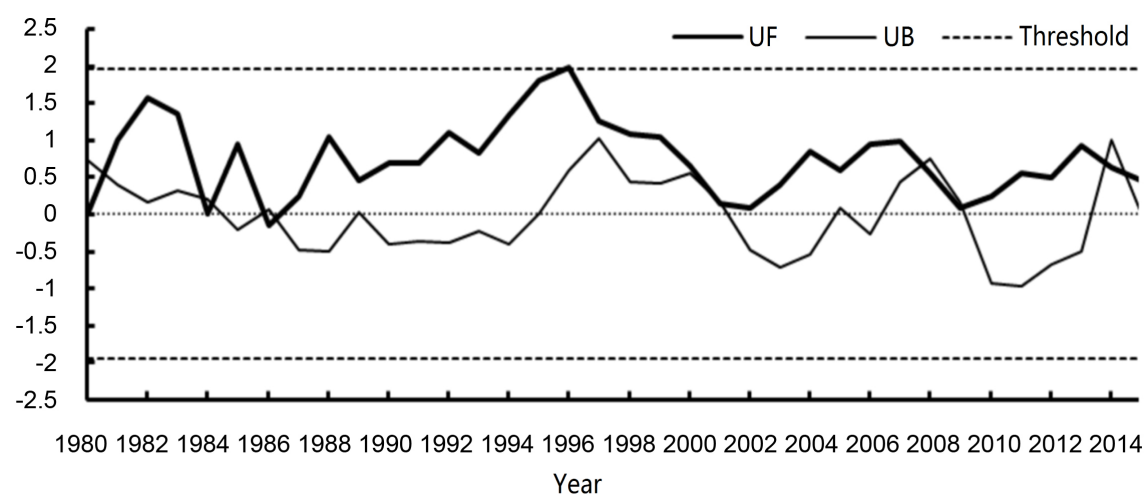

Figure 3. The $\mathrm{M}-\mathrm{K}$ test of number of shout-time heavy rainfall during the flood season in Shanxi in 1980-2015.

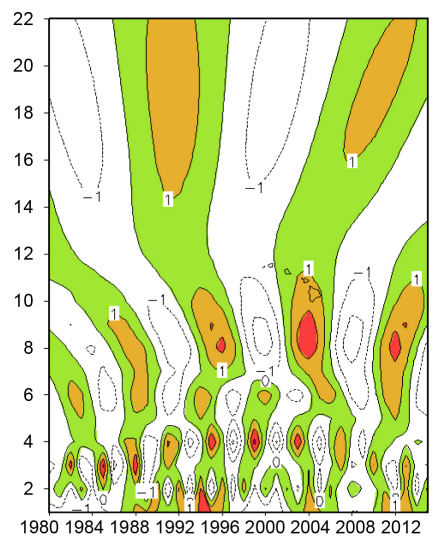

(a)

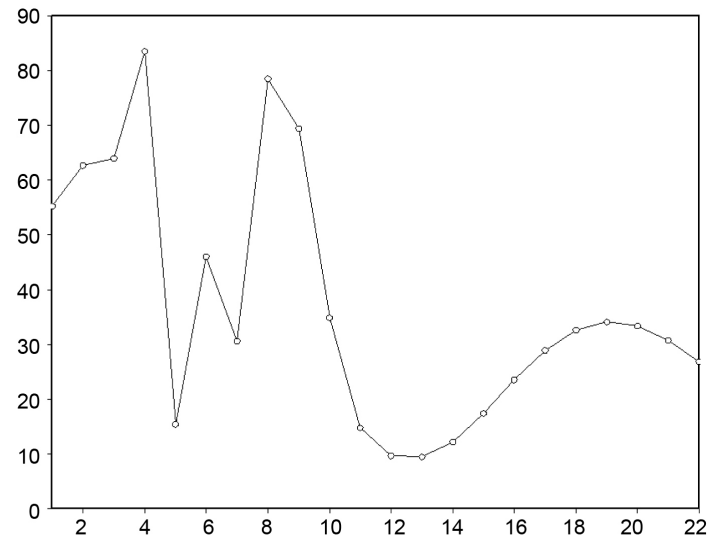

(b)

Figure 4. The wavelet analysis (a) and variance (b) of shout-time heavy rainfall stations.

years, the wavelet variance diagram of the short-term heavy precipitation station in Shanxi Province (Figure 4(b)) has three distinct peaks, which are the time scales of 4,6 , and 8 years. The maximum peak corresponds to a four-year time 
scale, indicating that the period of the four-year period is the strongest, and the second peak corresponds to the eight-year period of oscillation.

"Late-July-early-August" is the main period of Shanxi Province. From the monthly change of short-term heavy precipitation in Shanxi Province (Figure 5), it can be seen that short-term heavy precipitation began to appear in May; the shortest heavy rainfall in July has the most stations, which is 1580 stations, accounting for $45 \%$ of the total; followed by August, it was 1186 stations, accounting for $34 \%$ of the total; July-August short-term heavy precipitation stations accounted for $79 \%$ of the total; in September, it decreased rapidly. The annual variation of precipitation in different magnitudes is basically the same, but the proportion of stations in July-August has increased. Among them, the station with 1 hour precipitation in the range of $20 \mathrm{~mm}-30 \mathrm{~mm}$ accounts for $78 \%$ of the total, $30 \mathrm{~mm}$. The station of $\sim 40 \mathrm{~mm}$ accounts for $82 \%$ of the total number of the order, the station of $40 \mathrm{~mm}-50 \mathrm{~mm}$ accounts for $86 \%$ of the total number of the order, and the station of one hour precipitation $\geq 50 \mathrm{~mm}$ accounts for $88 \%$ of the total.

Daily changes can be used to reveal changes in short-term heavy precipitation in a single day. The daily variation of the number of strong precipitations from 5 to 9 months and years is analyzed. The number of occurrences of short-term heavy precipitation in each period is obtained, and the period of occurrence of short-term heavy precipitation in one day is further analyzed.

Figure 6 shows the daily variation characteristics of short-term heavy rainfall from May to September in Shanxi Province from May to September. From the perspective of time-lapse evolution, there are three peaks in May, and the strongest time is between 20:00 and 22:00.

The number of short-term heavy precipitation occurred was 11 to 13 times, followed by 16:00 to 18:00 and 00:00 to 02:00; the strongest peak in June appeared around 16:00, reaching 49 times, 16:00 - 20:00. This period of time, the number of occurrences of strong precipitation is relatively high, and the number of occurrences in other periods is small. July and June are similar. These times

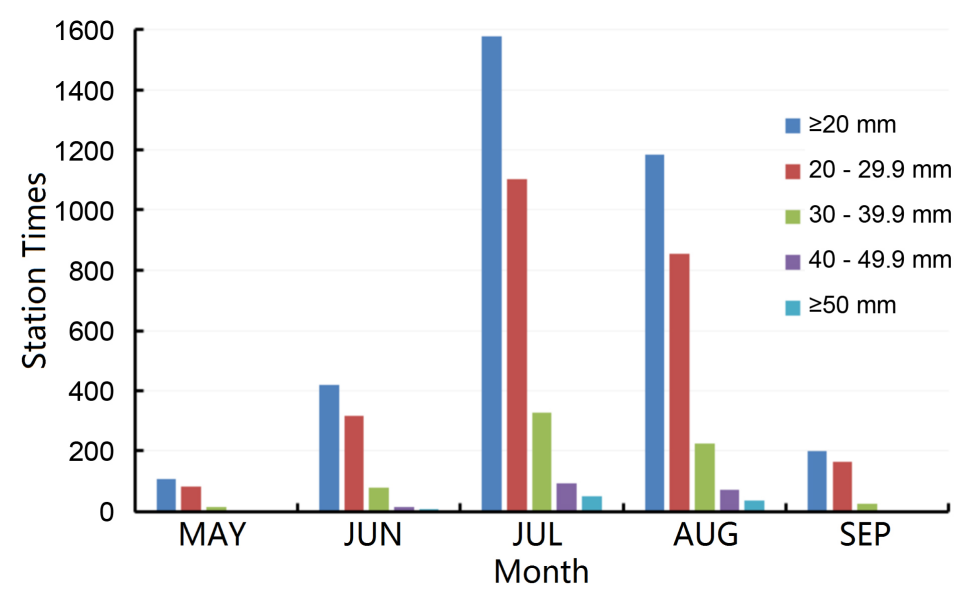

Figure 5. The monthly change of shout-time heavy rainfall number during the flood season in Shanxi. 
(a)
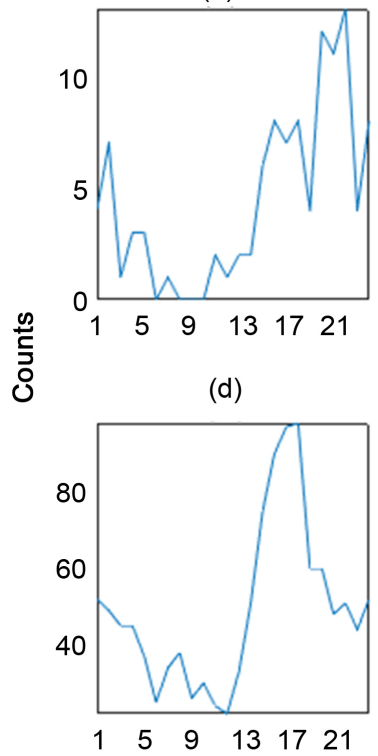

(b)

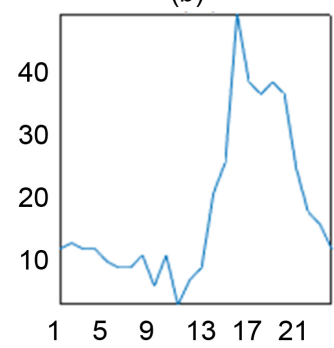

(e)

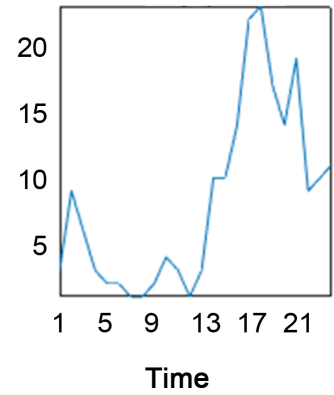

(c)

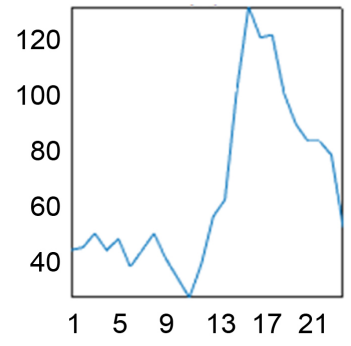

(f)

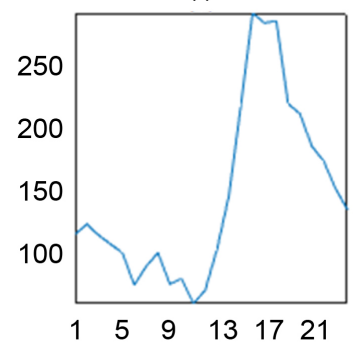

Figure 6. The hourly distributions of times of shout-time heavy rainfall during May-September and year in 1980-2015 ((a) May; (b) June; (c) July; (d) August; (e) September; (f) Year).

are from 16:00 to 20:00, but the strongest peak is around 17:00, and the number of times is more than 130. In August, the strongest peak was around 18:00, the number of times was 98, and from 16:00 to 18:00, there was a period of short-term heavy precipitation. In September, there were two peaks, which were around 17:00 to 18:00 and 21:00, and the number of times decreased. The peak time was only about 23 times.

\subsection{Spatial Distribution Characteristics}

Figure 7 shows the average distribution of short-term heavy precipitation stations in the months and years from May to September in 1980-2015. From the distribution of each month, in May (a) there were few short-term heavy precipitation events in Shanxi Province, including no short-term heavy precipitation in the northern margin, near Chenzhou and southern Jinzhong, and the remaining stations were at 0.2 times/year. Below, the large value area is located in the southwestern part of Shanxi, with the highest being Jincheng 0.19 times/year, showing that the southwest is significantly more than the rest of the province. In June (b), the number of short-term heavy precipitation stations increased, generally above 0.05 times/year, more in the south than in the north, more in the east than in the west, and a high-value center in the southeast and central-eastern regions; The value center is in the Changzhi-Jincheng area, and the high-value center in the central and eastern parts is in the area of Yangquan-Jindong Middle Mountain. It is the strongest in Gaoping in Jincheng, reaching 0.36 times/year. In July (c), the number of short-term heavy precipitation stations increased significantly, but the overall low-value range was reduced. 

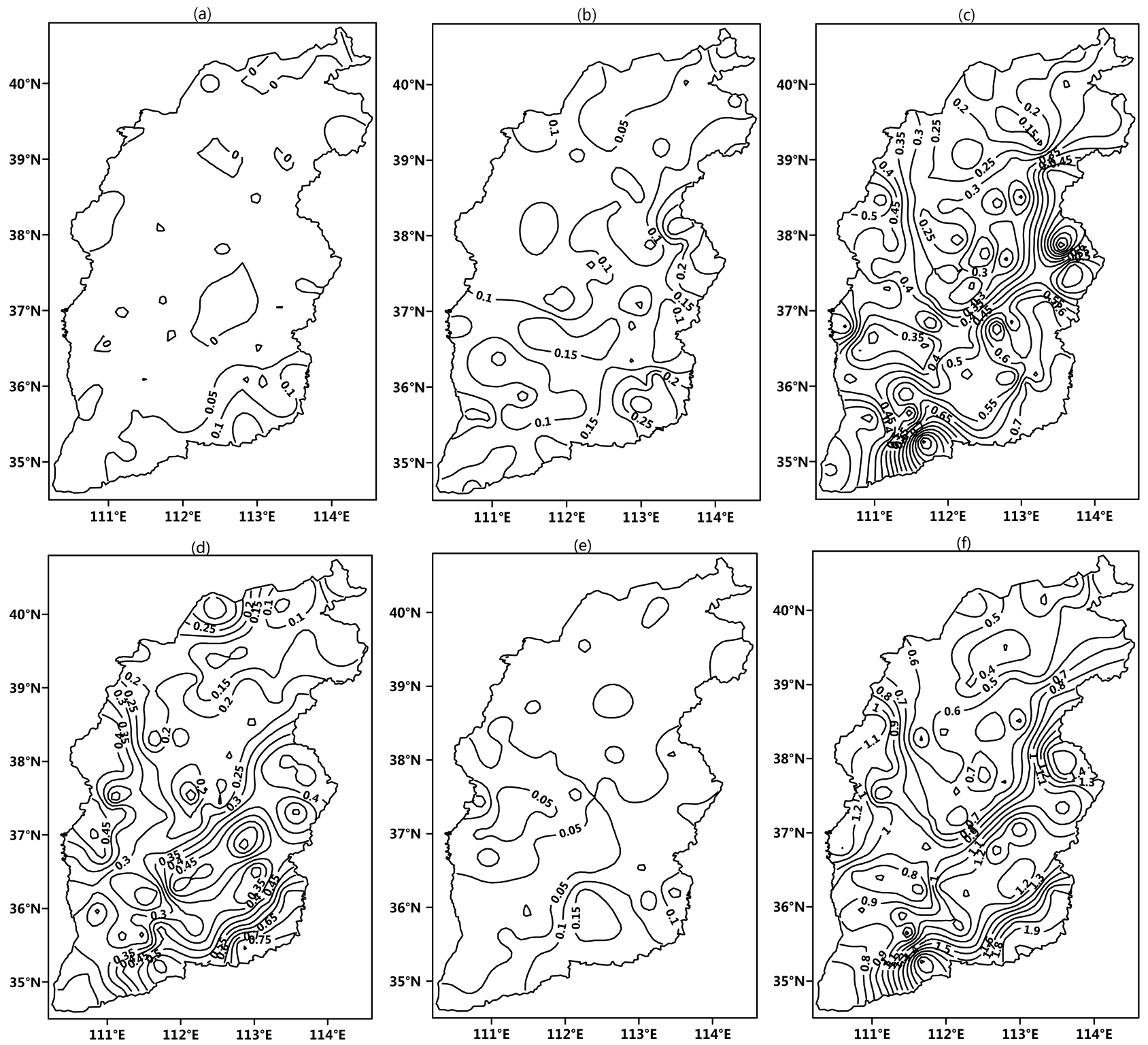

Figure 7. The monthly and yearly mean number distributions of short-time heavy rainfall during 1980-2015 ((a) May; (b) June; (c) July; (d) August; (e) September; (f) Year).

The high-value center in Yangquan area is slightly northward, corresponding to the south of Yangquan-Xinyang-Heshun-Heshun has a low-value center; the southeastern part of the high-value center has expanded significantly; the northwestern part of Shanxi's Luliang and Linyi West have two weak High-value center; the center of the southwestern part of the mountain (the Yuncheng distort) has a maximum value center of 1.08 times/year. August (d) was slightly lower than that in July, and the high-value center was in line with the July position. The extreme center was Jincheng, which was 0.81 times/year. In September (e), the number of short-term heavy precipitation stations decreased significantly, which was consistent with the distribution in May. However, all stations had short-term heavy precipitation, and the extreme value was located at LinfenAnze 
Station, which was 0.19 times/year.

From the average (f) average short-term heavy precipitation station distribution map of the whole flood season, it can be seen that the distribution of high and low values is consistent with the distribution in July, and the large-value centers are Jincheng Station and Yuncheng Henqu Station, respectively, 1.98 times/Year and 2.05 times/year.

\subsection{Relationship between Short-Term Heavy Precipitation and Total Precipitation during Flood Seasons}

Since the annual precipitation in Shanxi Province is mainly concentrated in the flood season, the total precipitation in all flood seasons can generally reflect the drought and flood conditions in the current year. In order to understand the relationship between the short-term heavy rainfall in the flood season in Shanxi Province and the flood and drought characteristics in the flood season, Figure 8 shows the Shanxi Province. The average annual distribution of total precipitation during the flood season, and the correlation coefficient between the total precipitation of each station in each flood season and the number of short-term heavy precipitation in the same year. It can be seen from Figure 8(a) that the average total precipitation in the flood season in Shanxi Province is between 175 and $460 \mathrm{~mm}$, showing a distribution of less south to north and less in east and west, similar to the distribution in Figure 7(f). The correlation coefficient between the average total precipitation in the flood season in Shanxi Province and the average short-term heavy precipitation station in the 36 years was calculated to be 0.74 , and the significance test was passed through 0.001. In Figure 8(b), the annual total precipitation in each station shows a good correlation with most of the short-term heavy precipitation stations in the same year. Only the northern
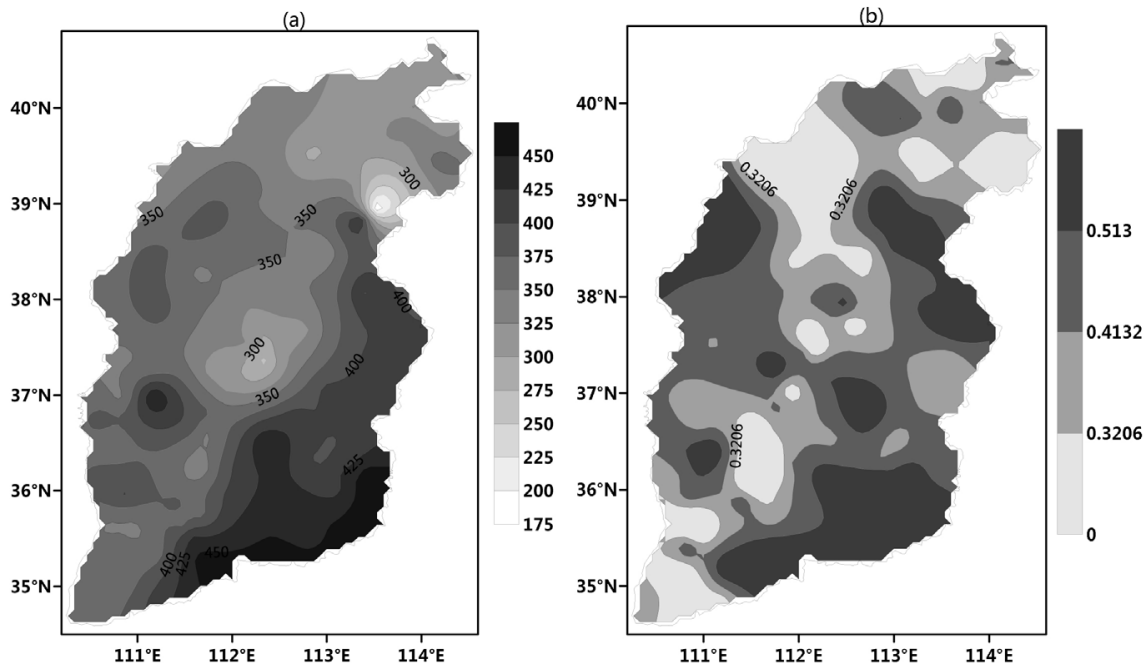

Figure 8. Annual average distribution ((a) unit: $\mathrm{mm}$ ) of precipitation during the flood season, correlation coefficient distribution between annual precipitation during the flood season and the times of short-time heavy rainfall at the same periods on every station in Shanxi ((b), $\alpha=0.05, r=0.3206 ; \alpha=0.01, r=0.4132 ; \alpha=0.001, r=0.513)$. 
and southwest parts, as well as the central part, have poor correlation, and the total precipitation is larger. The better the correlation between the place and the short-term heavy precipitation.

Since the annual precipitation in Shanxi Province is mainly concentrated in the flood season, the total precipitation in all flood seasons can generally reflect the drought and flood conditions in the current year. In order to understand the relationship between the short-term heavy rainfall in the flood season in Shanxi Province and the flood and drought characteristics in the flood season, Figure 8 shows the Shanxi Province. The average annual distribution of total precipitation during the flood season, and the correlation coefficient between the total precipitation of each station in each flood season and the number of short-term heavy precipitation in the same year. It can be seen from Figure 8(a) that the average total precipitation in the flood season in Shanxi Province is between 175 and $460 \mathrm{~mm}$, showing a distribution of less south to north and less in east and west, similar to the distribution in Figure 7(f). The correlation coefficient between the average total precipitation in the flood season in Shanxi Province and the average short-term heavy precipitation station in the 36 years was calculated to be 0.74 , and the significance test was passed through 0.001. In Figure 8(b), the annual total precipitation in each station shows a good correlation with most of the short-term heavy precipitation stations in the same year. Only the northern and southwest parts, as well as the central part, have poor correlation, and the total precipitation is larger. The better the correlation between the place and the short-term heavy precipitation.

\section{Conclusion and Discussion}

From 1980 to 2015, from May to September, an average of 97 stations of short-term heavy rainfall occurred each year in Shanxi Province. Among them, the precipitation in one hour is mainly rain intensity of 20 to $30 \mathrm{~mm}$. From the long-term trend of 36 a, the short-term heavy precipitation station showed an increasing trend with obvious interdecadal variations. In 1986-1998 and 2008-2014, the short-term heavy rainfall in Shanxi Province was relatively long-term, and the rest of the period was relatively less, and with two cycles of 4 years and 8 years.

In the past 36 years, the short-term heavy precipitation in Shanxi Province showed a single-peak shape from May to September, with the most stations occurring from July to August, accounting for $79 \%$ of the total, and the maximum rainfall intensity; precipitation of different magnitudes. The annual change is basically the same, but the proportion of stations in July-August has increased. Short-term heavy precipitation in the flood season in Shanxi Province is likely to occur from 16:00 to 18:00 in the afternoon, and it is less likely to have short-term heavy precipitation from midnight to noon. The time of occurrence of short-term heavy precipitation in different months is slightly different. The main peaks in June, July and August are at 16,17, and 18, respectively, and one hour 
later, and short-term heavy precipitation in May and September.

The spatial distribution of short-term heavy precipitation weather in the flood season in Shanxi Province has obvious geographical differences, and the monthly distribution is not the same, but the overall distribution is less in the south and less in the north, and the distribution in the east and the west is less, and it is prone to short-term strong. The precipitation areas are mainly distributed in Yangquan, Changzhi, Jincheng, Linyi and Yuncheng eastern areas in the southern and eastern mountainous areas.

The annual average total precipitation in the flood season in Shanxi Province is similar to the annual average short-term heavy precipitation station distribution. There is a good correlation between the total precipitation in the flood season and the short-term heavy precipitation station in the flood season. The more total precipitation is. The better the local correlation, the short-term heavy precipitation accounts for an important proportion of precipitation in the flood season in Shanxi, and is an important feature of precipitation during the flood season. Since the data selected in this paper are the whole point data, it may cause some short-term heavy precipitation time that exceeds the specified threshold for $1 \mathrm{~h}$ to be divided into two stages, but does not reach the statistical standard of this paper, so short-term heavy precipitation occurs. The frequency should be higher. In recent years, with the abundance of meteorological observation data, the distribution characteristics of short-term heavy precipitation with 10 min precipitation data may be more detailed and comprehensive.

\section{Conflicts of Interest}

The authors declare no conflicts of interest regarding the publication of this paper.

\section{References}

Abdullayev, N., Dyshin, O., \& Dadashova, D. (2017). Identification of the Oscillator Parameters of the Van der Pol Oscillator Using Wavelet Analysis. Open Access Library Journal, 4, 1-5.

Bera, S. (2017). Trend Analysis of Rainfall in Ganga Basin, India during 1901-2000. American Journal of Climate Change, 6, 116-131. https://doi.org/10.4236/ajcc.2017.61007

Cai, X., Ye, D., Sun, W. et al. (2014). Characteristics of Short-Term Precipitation Changes in Flood Season in Shaanxi Province from 1961 to 2011. Plateau Meteorology, 33, 1618-1626.

Chen, W., Zheng, Y., Zhang, X. et al. (2013). Distribution and Diurnal Variation of Short-Term Heavy Rainfall in China during Warm Season and Its Relationship with Diurnal Variation of Mesoscale Convective System. Acta Meteorologica Sinica, 71, 365-382.

Gu, X. (2013). Analysis of Short-Term Heavy Rainfall and Its Cloud Characteristics in Henan Province. Meteorological and Environmental Sciences, 36, 15-20.

Guo, H., Huang, T., Deng, M. et al. (2007). Characteristics of Heavy Precipitation and Flood Disasters in the 45a Area of Tianshui, Gansu Province. Journal of Glaciology and 
Geocryology, 29, 808-812.

Han, N., \& Miao, C. (2012). Statistical Characteristics of Short-Term Heavy Rainfall in the Five-September Period of Shaanxi, Gansu and Ningxia Provinces in Recent 6 Years. Journal of Applied Meteorology, 23, 691-701.

Hao, Y., Yao, Y., Zheng, Y. et al. (2012). Multi-Scale Analysis and Proximity Warning of Short-Term Heavy Precipitation. Meteorology, 38, 903-912.

Joseph, A., Sisodia, G., \& Tiwari, A. (2015). The Inter-Temporal Causal Nexus between Indian Commodity Futures and Spot Prices: A Wavelet Analysis. Theoretical Economics Letters, 5, 312-324. https://doi.org/10.4236/tel.2015.52037

Koudahe, K., Kayode, A., Samson, A., Adebola, A., \& Djaman, K. (2017). Trend Analysis in Standardized Precipitation Index and Standardized Anomaly Index in the Context of Climate Change in Southern Togo. Atmospheric and Climate Sciences, 7, 401-423. https://doi.org/10.4236/acs.2017.74030

Li, Z., Song, Y., \& Ding, D. (2010). Characteristics of Extreme Precipitation in the Main Flood Season of Shanxi Province. Climate and Environment Research, 15, 433-442.

Banovic, M., Nunes, L., \& Arsenijevic, V. (2013). An Application of Wavelet Analysis to Meat Consumption Cycles. Food and Nutrition Sciences, 4, 252-261.

Peng, F., Wu, G., \& Du, X. (2012). Analysis of Temporal and Spatial Characteristics of Short-Term Precipitation in Flood Season in Guizhou Province. Meteorology, 38, 307-313.

Ragatoa, D., Ogunjobi, K., Okhimamhe, A., Francis, S., \& Adet, L. (2018). A Trend Analysis of Temperature in Selected Stations in Nigeria Using Three Different Approaches. Open Access Library Journal, 5, 1-17.

Shen, C., Yan, T., Liu, D. et al. (2015). Characteristics of Short-Term Heavy Rainfall in Nanjing from 2008 to 2012. Journal of Meteorology and Environment, 31, 28-33.

Shen, W., Yuan, H., Chen, W. et al. (2017). Analysis of Temporal and Spatial Uneven Characteristics of Short-Term Heavy Rainfall in Warm Season in Jiangsu Province. Journal of Atmospheric Sciences, 40, 453-462.

Wang, G., \& Wang, L. (2013). Temporal and Spatial Distribution Characteristics of Short-Term Heavy Rainfall in Summer in Beijing. Torrential Rain, 32, 276-279.

Wang, S., Zhao, G., Zhao, Y., \& Shen, L. (2017). Multi-Scale System Interaction Research of a Torrential Rainfall Process in Shanxi in July 2016. Journal of Arid Meteorology, 35, 151-161.

Wang, W., Huang, Z., Zou, S. et al. (2016). Study on Characteristics and Forecasting Indexes of Short-Term Heavy Precipitation in Dalian Area. Journal of Meteorology and Environment, 32, 32-38.

Wang, Y., Zhang, H., Guo, X. et al. (2012). Variation Characteristics of Extreme Events of High Temperature and Heavy Precipitation in Recent 48 Years in Shanxi Province. Arid Zone Research, 29, 289-295.

Yang, J., Jiang, Z., Wang, P. et al. (2018). Temporal and Spatial Distribution Characteristics of Annual Extreme Precipitation Events in China. Climatic and Environmental Research, 13, 75-83.

Yang, S., Hao, S., Feng, X. et al. (2010). Analysis and Forecasting of Short-Term Heavy Precipitation in Hangzhou. Bulletin of Science and Technology, 26, 2378-2390.

Yao, L., Zhao, S., Zhao, C. et al. (2010). Time-Space Distribution and Return Period Estimation of Time-Dependent Rain Intensity in Central and Eastern China. Journal of Geographical Sciences, 65, 293-300.

Yin, C., Liang, Y., Geng, G. et al. (2010). Characteristics of Short-Term Heavy Precipita- 
tion in Jinan Urban Area. Meteorological Science, 30, 262-267.

Yin, S., Gao, G., Li, W. et al. (2012). Trends of Seasonal Precipitation in the Haihe River Basin in Summer from 1961 to 2004. Science in China: Earth Sciences, 42, 256-266.

Zhang, G., Guo, M., \& Zhao, H. (2008). Characteristics of Precipitation Change in Shanxi Province in Recent 45 Years. Arid Zone Research, 25, 858-861.

Zhang, H., Qu, P., \& Tang, H. (2011). Characteristics of Hourly Precipitation in Southwest China from 1961 to 2000. Progress in Climate Change Research, 7, 8-13.

Zhao, G., Zhao, C., Li, X. et al. (2006). Analysis of Climate Change in Shanxi Province in Recent 47 Years. Arid Zone Research, 23, 500-505. 